\title{
Phase I/II study of S- I combined with paclitaxel in patients with unresectable and/or recurrent advanced gastric cancer
}

\author{
E Mochiki*,', T Ohno', Y Kamiyama', R Aihara', N Haga ${ }^{2}$, H Ojima ${ }^{3}$, J Nakamura ${ }^{4}$, H Ohsawa ${ }^{5}$, T Nakabayashi', \\ K Takeuchi', T Asao', H Kuwano' and the North Kanto Gastric Cancer Study Group \\ 'Department of General Surgical Science, Graduate School of Medicine, Gunma University, 3-39-22, Showa-machi, Maebashi, Gunma 37I -85 II, Japan; \\ ${ }^{2}$ Department of Surgery, Gunma Cancer Center Hospital, Gunma, Japan; ${ }^{3}$ Department of Surgery, Saiseikai Maebashi Hospital, Gunma, Japan; \\ ${ }^{4}$ Department of Surgery, Ohmiya Red Cross Hospital, Saitama, Japan; ${ }^{5}$ Department of Surgery, Fujioka General Hospital, Gunma, Japan; ${ }^{6}$ Department of \\ Surgery, Gunma Cardiovascular Center, Gunma, Japan; ${ }^{7}$ Department of Surgery, Tone Chuo Hospital, Gunma, Japan
}

Both paclitaxel and S-I are effective against gastric cancer, but the optimal regimen for combined chemotherapy with these drugs remains unclear. This phase I/II study was designed to determine the maximum tolerated dose (MTD), recommended dose (RD), dose-limiting toxicity (DLT), and objective response rate of paclitaxel in combination with S-I. S-I was administered orally at a fixed dose of $80 \mathrm{mg} \mathrm{m}^{-2}$ day $^{-1}$ from days I to 14 of a 28-day cycle. Paclitaxel was given intravenously on days I, 8, and I5, starting with a dose of $40 \mathrm{mg} \mathrm{m}^{-2} \mathrm{day}^{-1}$. The dose was increased in a stepwise manner to $70 \mathrm{mg} \mathrm{m}^{-2}$. Treatment was repeated every 4 weeks unless disease progression was confirmed. In the phase I portion, 17 patients were enrolled. The MTD of paclitaxel was estimated to be $70 \mathrm{mg} \mathrm{m}^{-2}$ because $40 \%$ of the patients given this dose level (two of five) had DLT. The RD was determined to be $60 \mathrm{mg} \mathrm{m}^{-2}$. In the phase II portion, 24 patients, including five with assessable disease who received the RD in the phase I portion, were evaluated. The median number of treatment courses was six (range: 1 - 17). The incidence of the worst-grade toxicity in patients given the RD was 28 and $8 \%$, respectively. All toxic effects were manageable. The response rate was $54.1 \%$, and the median survival time was I5.5 months. Our phase I/II trial showed that S-I combined with paclitaxel is effective and well tolerated in patients with advanced gastric cancer.

British Journal of Cancer (2006) 95, 1642-1647. doi:I0.1038/sj.bjc.6603497 www.bjcancer.com

Published online 28 November 2006

(c) 2006 Cancer Research UK

Keywords: advanced gastric cancer; S-I; paclitaxel

Patients with unresectable and recurrent gastric cancer have extremely poor outcomes, with 5-year survival rates of less than $5 \%$ (Parker et al, 1997). Various chemotherapy regimens have been developed, but median survival in patients with unresectable or recurrent gastric cancer (or both) who receive chemotherapy remains less than 9-12 months (Wils et al, 1991; Kim et al, 1993; Koizumi et al, 2003; Ohtsu et al, 2003; Ajani et al, 2006b). Randomised phase III studies of combination chemotherapy for unresectable advanced gastric cancer reported median survival times (MSTs) of 5-9.6 months and overall response rates of 9-46\% (Webb et al, 1997; Vanhoefer et al, 2000; Ross et al, 2002; Ohtsu et al, 2003). Combination chemotherapy thus appears to contribute only marginally to survival. New agents and combination chemotherapy regimens are needed to achieve greater survival benefits in far-advanced gastric cancer.

$\mathrm{S}-1$, a fourth-generation oral fluoropyrimidine, is an oral formulation combining tegafur, 5-chloro-2,4-dihydroxypyridine, and potassium oxonate at a molar ratio of 1:0.4:1 (Takechi et al, 1997). S-1 is acknowledged to be a useful anticancer drug in Japan.

*Correspondence: Dr E Mochiki; E-mail: emochiki@yahoo.co.jp Received 15 August 2006; revised 26 October 2006; accepted 29 October 2006; published online 28 November 2006
Phase I and early phase II studies of S-1 as a single agent proposed $80 \mathrm{mg} \mathrm{m}^{-2}$ day $^{-1}$ given orally for 28 consecutive days, followed by a 2-week rest period, as the tentative recommended dosage (Horikoshi et al, 1996; Sugimachi et al, 1999). A number of studies have reported that S-1 monotherapy is effective against gastric cancer, with response rates ranging from 26 to 53\% (Horikoshi et al, 1996; Sakata et al, 1998; Koizumi et al, 2000; Chollet et al, 2003). The toxicity profile of S-1 in European studies apparently differs from that in Japanese studies, with more diarrhoea and hand-foot syndrome and less myelotoxicity (Chollet et al, 2003). In one early phase II clinical trial of S-1, the response rate was $53.6 \%$ (15 out of 28), and the median survival period was 298 days in Japanese patients with advanced gastric cancer (Horikoshi et al, 1996). Two late phase II studies of S-1 in advanced gastric cancer, which used similar treatment regimens, demonstrated high response rates of 49 and 44\%, respectively (Sakata et al, 1998; Koizumi et al, 2000). These results suggested that S-1 is likely to become a key drug for the management of advanced gastric cancer.

Paclitaxel is a taxane derivative that was originally isolated from Taxus brevifolia, a type of Western yew (Wani et al, 1971). Paclitaxel, a newer taxane, has been shown to be effective against a variety of cancers, including breast cancer (Holmes et al, 1991), ovarian cancer (Einzig et al, 1992), and lung cancer (Chang et al, 1993). Paclitaxel is also an effective drug for gastric cancer, with 
response rates ranging from 20 to $28 \%$ in single-agent phase II studies (Ajani et al, 1998; Ohtsu et al, 1998; Yamada et al, 2001; Yamaguchi et al, 2002). Ajani et al (1998) reported that a 24-h infusion of paclitaxel is associated with a higher response rate and milder haematological toxicity than a 3-h infusion of an equivalent dose in patients with gastric cancer. The recommended optimal dose of paclitaxel in Japan was determined to be $210 \mathrm{mg} \mathrm{m}^{-2}$ once every 3 weeks (Yamaguchi et al, 2002). Recently, good results have been obtained with a weekly regimen of paclitaxel in patients with ovarian cancer and gastric cancer (Fennelly et al, 1997; Arai et al, 2003; Hironaka et al, 2006). The use of weekly regimens of paclitaxel, used mainly as second-line chemotherapy, has increased in Japan because of milder haematological toxicity as compared with regimens administering paclitaxel once every 3 weeks.

This multi-institution phase I/II study was designed to evaluate the efficacy and toxicity of combination therapy with paclitaxel, given in increasing doses, plus a fixed dose of S-1 $\left(80 \mathrm{mg} \mathrm{m}^{-2}\right)$ in patients with untreated, advanced gastric cancer. All participating centres belonged to the North Kanto Gastric Cancer Study Group.

\section{PATIENTS AND METHODS}

\section{Patient eligibility}

Eligible patients had histologically proved unresectable or recurrent gastric cancer. Up to one regimen of prior chemotherapy was allowed (adjuvant chemotherapy was allowed provided that at least 28 days had elapsed since the last treatment), except for prior treatment with taxanes (paclitaxel or docetaxel).

Other inclusion criteria were as follows: an age of 20-75 years; a performance status of $0-1$ (Eastern Clinical Oncology Group); an estimated life expectancy of more than 3 months; a white blood cell count between 4000 and $12000 \mathrm{~mm}^{-3}$; an absolute neutrophil count of over $2000 \mathrm{~mm}^{-3}$, a platelet count of over $100000 \mathrm{~mm}^{-3}$, a haemoglobin level of over $8.0 \mathrm{~g} \mathrm{dl}^{-1}$; aspartate aminotransferase and alanine aminotransferase levels within two times the upper limit of normal for the institution; a serum bilirubin level of less than $1.5 \mathrm{mg} \mathrm{dl}^{-1}$; a serum creatinine level within the upper limit of the normal value for the institution; a 24-h creatinine clearance of more than $50 \mathrm{ml} \mathrm{min}^{-1}$; and a normal electrocardiogram. Only patients who could swallow tablets were eligible. Patients were excluded if they had brain metastases, severe comorbid conditions, active double cancers, a past history of drug allergy, or were unable to comply with the protocol requirements. Pregnant women were also excluded. Written informed consent was obtained from all patients before study entry. This study was approved by the Ethics Committees at the participating sites.

\section{Treatment regimen and dose-escalation schedule}

S-1 (Taiho Pharmaceutical Co., Ltd., Tokyo, Japan) was given orally twice daily after meals at a fixed dose of $80 \mathrm{mg} \mathrm{m}^{-2}$ day $^{-1}$ for 14 consecutive days, followed by a 14-day rest period; this cycle was repeated every 4 weeks. The dose of $S-1$, decided on the basis of the patients' body surface area (BSA), was $40 \mathrm{mg}$ (BSA $<1.25 \mathrm{~m}^{2}$ ), $50 \mathrm{mg}\left(\right.$ BSA $\left.1.25-1.5 \mathrm{~m}^{2}\right)$, or $60 \mathrm{mg}\left(\right.$ BSA $\left.\geqslant 1.5 \mathrm{~m}^{2}\right)$. Paclitaxel (Taxol; Bristol-Myers Squibb, Tokyo, Japan) was administered intravenously over the course of $60 \mathrm{~min}$ on days 1 , 8 , and 15 . To prevent hypersensitivity reactions, all patients received $20 \mathrm{mg}$ of dexamethasone intravenously, $50 \mathrm{mg}$ of diphenhydramine orally, and $50 \mathrm{mg}$ of ranitidine intravenously $1 \mathrm{~h}$ before paclitaxel infusion. The initially administered dose of paclitaxel was $40 \mathrm{mg} \mathrm{m}^{-2}$ (dose level 1). The dose was scheduled to be increased in $10 \mathrm{mg} \mathrm{m}^{-2}$ increments to $70 \mathrm{mg} \mathrm{m}^{-2}$ (dose level 4), unless the maximum tolerated dose (MTD) was reached. At least three patients received each dose level. If one of the three patients at a given dose had any dose-limiting toxicity (DLT), three other patients were assigned to receive the same dose. If one of the resulting six patients had DLT, the dose could be increased to the next level; if two or more patients had DLT, that level was deemed the MTD. If DLT occurred in two or all three of the patients initially assigned to a given dose level, that level was also considered the MTD. The MTD was thus defined as the dose at which $>33 \%$ of the patients had DLTs during the first course of treatment. The recommended dose (RD) for phase II studies was defined as one level below the MTD. Toxicity was graded according to the National Cancer Institute common toxicity criteria, version 2.0. Dose-limiting toxicity was defined as follows: grade 4 leucopenia/neutropenia, febrile grade 3 neutropenia lasting for more than 4 days, grade 3 thrombocytopenia, and any grade 3 or above non-haematological toxicity (excluding anorexia, nausea, vomiting, alopecia, and general fatigue).

\section{Response evaluation and toxicity}

Tumour response was evaluated by computed tomographic (CT) scans for each course of treatment. Imaging studies were repeated to confirm response at least 4 weeks (for complete or partial responses) after first documenting a given response. Thereafter, tumour response was evaluated by CT scanning every two cycles. Radiographs of all assessable patients were also reviewed externally to confirm investigator-designated responses. Tumour response was objectively evaluated according to guidelines for the evaluation of the response of solid tumours to treatment (Therasse et al, 2000).

\section{End points and statistical analysis}

The primary study end point was the definition of the MTD and DLT of the described regimen of TS-1 plus paclitaxel. The MTD and recommended dose were further examined in additional patients to confirm their toxicity/safety profile and to ensure their suitability for future phase II trials. Additional study end points were to determine (i) the objective response rate according to the RECIST criteria; (ii) progression-free survival (calculated from the date of starting treatment to the date of progression or relapse); and (iii) overall survival. Survival from the date of study entry was estimated using the Kaplan-Meier product-limit method.

The calculation of sample size for the phase II portion of the study was based on a target activity level of $60 \%$ and a minimum activity level of $30 \%$, at a significance level of 0.05 and $\beta$ error $=0.1$. The required number of patients was estimated to be 21 .

\section{RESULTS}

\section{Patients' characteristics}

Between August 2002 and April 2005, a total of 36 patients were enrolled. In the phase I part, 17 patients were studied between August 2002 and January 2004. The patients' characteristics are summarised in Table 1. Their median age was 62 years (range: 44-71 years). One patient had undergone a prior gastrectomy, and another patient had received adjuvant chemotherapy with S-1 alone before study entry. Histologically, 12 patients had intestinaltype adenocarcinoma, and five patients had diffuse-type adenocarcinoma. The sites of metastasis were the liver in two patients, the lymph nodes in 15 , and the peritoneum in five. One patient (level 3) had a non-measurable metastatic lesion in the peritoneum.

In the phase II part of the study, 19 patients were enrolled between August 2004 and April 2005 (Table 1). Their median age was 63 years (range: $48-75$ years). Four patients had undergone a prior gastrectomy and received adjuvant chemotherapy with S-1 
alone before study entry. Histologically, 13 patients had intestinaltype adenocarcinoma, and six patients had diffuse-type adenocarcinoma. All 19 patients had measurable metastatic lesions, involving the lymph nodes in 14 patients and the liver in six. Nine patients $(47 \%)$ had non-measurable metastatic lesions in the peritoneum.

A total of 201 courses of treatment were given. The median number of treatment courses was four (range: 1-13) and six (range: 1-17) in the phase I and II portions, respectively. The median duration of therapy per patient was 251 days (range: $28-$ 523 ) in the phase II portion.

\section{Determination of MTD}

Toxic effects are summarised in Table 2. In the phase I part of the study, all patients were evaluated for adverse reactions, and 16 completed one or more cycles of treatment. None of the six patients given dose level 1 or 2 had DLT. At level 3, one patient had grade 3 leucopenia during the first cycle, and another had grade 3

Table I Patients' characteristics

\begin{tabular}{lcc}
\hline & Phase I (n= I7) & Phase II (n=19) \\
\hline Median age, years (range) & $64(44-7 \mid)$ & $63(48-75)$ \\
Male/female & $12 / 5$ & $15 / 4$ \\
Performance status & & \\
0 & 14 & 15 \\
I & 3 & 4 \\
Histological type & & \\
Intestinal & & 13 \\
Diffuse & 12 & 6 \\
Prior therapy & 5 & \\
$\quad$ None & & 15 \\
Gastrectomy & & 0 \\
$\quad$ Gastrectomy+chemotherapy & 15 & 4 \\
Site of metastasis & 1 & 6 \\
Liver & 1 & 14 \\
Lymph nodes & & 0 \\
Peritoneum & 2 & \\
\hline
\end{tabular}

anaemia during the second. Three other patients were then assigned to receive dose level 3 to reconfirm safety; none had DLT. At level 4 , one patient had grade 3 anorexia (20\%) with grade 3 diarrhoea (20\%) and vertigo (20\%) during the first cycle, whereas another had grade 3 hyperkalemia (20\%). The plasma potassium concentration increased after treatment with paclitaxel and then gradually fell to the normal range. Vertigo occurred 30-40 min after the administration of paclitaxel. These toxic effects repeatedly occurred after treatment with paclitaxel and resolved completely without any medication. They were therefore considered treatment-related. Dose-limiting toxicity occurred in two of the five patients given dose level 4 . On the basis of these results, dose level 4 was considered the MTD, and dose level 3 was determined to be the RD.

\section{Efficacy}

In the phase I portion, one of the 17 patients had no measurable lesions. Efficacy was evaluated in the other 16 patients. Seven

Table 3 Overall response to treatment

\begin{tabular}{|c|c|c|c|c|c|c|c|}
\hline & $n$ & CR & PR & SD & PD & NE & $\mathbf{R R}(\%)$ \\
\hline \multicolumn{8}{|l|}{ Phase I } \\
\hline Overall & 17 & 0 & 7 & 2 & 7 & 1 & 43.7 \\
\hline \multicolumn{8}{|l|}{ Level } \\
\hline 1 & 3 & 0 & 1 & 0 & 2 & 0 & 33.3 \\
\hline 2 & 3 & 0 & 2 & 1 & 0 & 0 & 66.6 \\
\hline 3 & 6 & 0 & 2 & 1 & 2 & I & 50.0 \\
\hline 4 & 5 & 0 & 2 & 0 & 3 & 0 & 40.0 \\
\hline \multicolumn{8}{|c|}{ Histological type } \\
\hline Intestinal & 12 & 0 & 4 & 2 & 5 & I & 36.3 \\
\hline Diffuse & 5 & 0 & 3 & 0 & 2 & 0 & 60.0 \\
\hline \multicolumn{8}{|l|}{ Phase $11^{\mathrm{a}}$} \\
\hline Overall & 24 & । & 12 & 6 & 5 & 0 & 54.1 \\
\hline \multicolumn{8}{|c|}{ Histological type } \\
\hline Intestinal & 17 & 1 & 9 & 3 & 4 & 0 & 58.8 \\
\hline Diffuse & 7 & 0 & 3 & 3 & 1 & 0 & 42.8 \\
\hline
\end{tabular}

$\mathrm{CR}=$ complete response; $\mathrm{PR}=$ partial response; $\mathrm{SD}=$ stable disease; $\mathrm{PD}=$ progres-

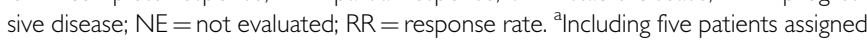
to level 3 in the phase I portion.

Table 2 Toxic effects and number of patients with toxicity according to the dose level of paclitaxel

\begin{tabular}{|c|c|c|c|c|c|c|c|c|}
\hline \multirow{2}{*}{$\begin{array}{l}\text { Paclitaxel } \\
\text { Grade }\end{array}$} & \multicolumn{2}{|c|}{ Level I $(n=3)$} & \multicolumn{2}{|c|}{ Level $2(n=3)$} & \multicolumn{2}{|c|}{ Level $3(n=6)$} & \multicolumn{2}{|c|}{ Level $4(n=5)$} \\
\hline & $1-2$ & $3-4$ & $1-2$ & $3-4$ & $1-2$ & $3-4$ & $1-2$ & $3-4$ \\
\hline \multicolumn{9}{|l|}{ Haematological } \\
\hline Leucopenia & 2 & 0 & । & 0 & 3 & । & 0 & 0 \\
\hline Neutropenia & 2 & 0 & 0 & 0 & 2 & 0 & 1 & 0 \\
\hline Anaemia & i & 0 & 2 & 0 & 2 & I & i & 0 \\
\hline Thrombocytopenia & 0 & 0 & 0 & 0 & 0 & 0 & 0 & 0 \\
\hline Anorexia & 0 & 0 & I & 0 & 2 & 0 & 0 & I \\
\hline Nausea & I & 0 & 0 & 0 & 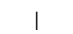 & 0 & I & 0 \\
\hline Diarrhoea & 0 & 0 & 0 & 0 & । & 0 & 0 & । \\
\hline Fatigue & 0 & 0 & 0 & 0 & 2 & 0 & 1 & 0 \\
\hline Stomatitis & 1 & 0 & 0 & 0 & 0 & 0 & 0 & 0 \\
\hline Rash & 0 & 0 & 0 & 0 & 0 & 0 & 1 & 0 \\
\hline Vertigo & 0 & 0 & 0 & 0 & 0 & 0 & 0 & 1 \\
\hline
\end{tabular}

AST = aspartate aminotransferase; ALT = alanine aminotransferase; $n=$ number of patients. National Cancer Institute common toxicity criteria (version 2). 
patients had a partial response (PR), two had stable disease (SD), and seven had progressive disease (PD), yielding a response rate of $43.7 \%$ in patients with assessable lesions (Table 3 ). The response rate was $36.3 \%$ (four out of 11 ) in the patients with intestinal-type adenocarcinoma and $60 \%$ (three out of five) in those with diffusetype adenocarcinoma (Table 3 ).

Twenty-four patients, including five enrolled in the phase I portion of the study, were evaluated to determine the response rate at the $\mathrm{RD}$ in the phase II portion. The overall response rate was $54.1 \%$ (95\% confidence interval (CI): $34.2-74.1 \%)$; one patient had a complete response (CR), 12 had PR, six had SD, and five had PD (Table 3$)$. The response rate according to pathological type was $58.8 \%$ (10 out of 17 ) for intestinal-type adenocarcinoma and $42.8 \%$ (three out of seven) for diffuse type. The median overall duration of response in the 13 responders in the phase II portion was 7.8 months (95\% CI, 4.2-10.1 months). The median time to progression (TTP) was 9.5 months (95\% CI, 5-11.6 months) in the phase II portion (Figure 1). Median survival time in the phase II portion was 15.5 months (95\% CI, 11.6-19.4 months), and the 1- and 2-year survival rates were 71.7 and $49.3 \%$, respectively (Figure 2).

\section{Toxicity}

In the phase II portion, the median number of courses administered was six (range: 1-17). In the 25 patients who

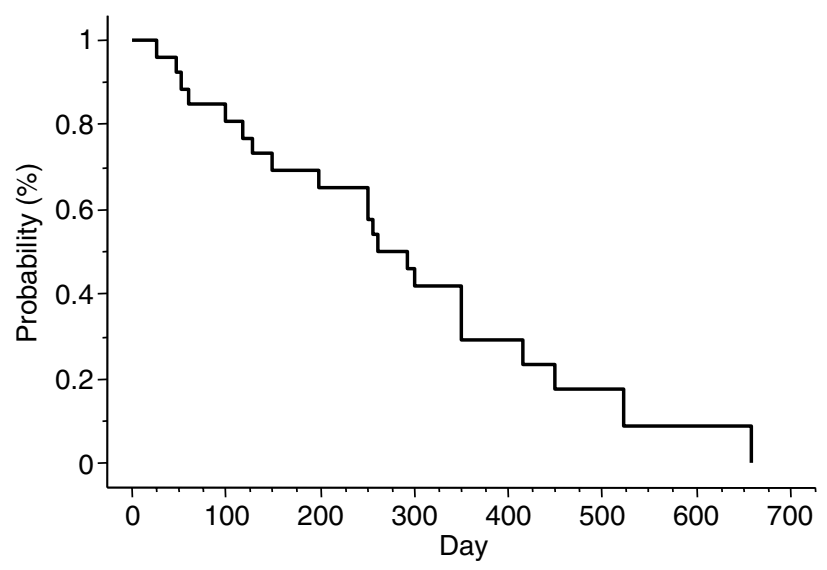

Figure I Cumulative probability of progression-free survival as estimated by the Kaplan-Meier method in 24 patients.

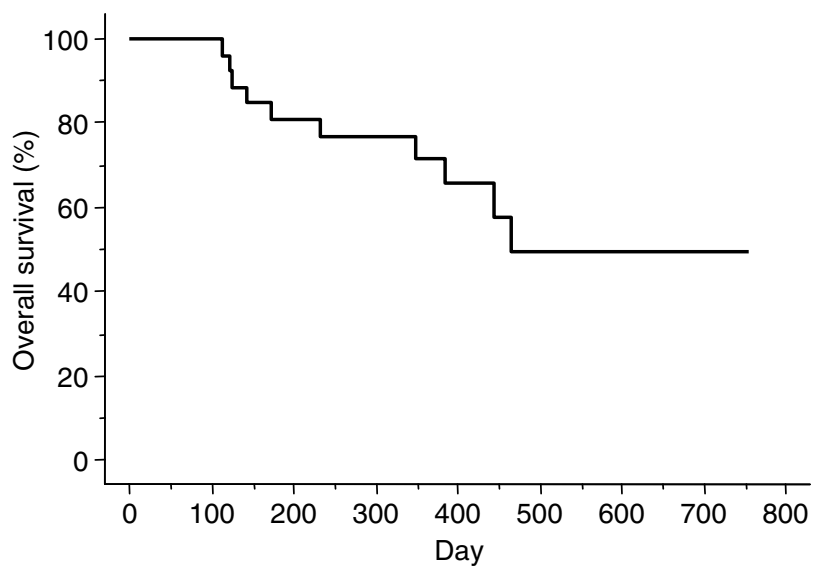

Figure 2 Cumulative probability of overall survival as estimated by the Kaplan-Meier method in 24 patients. received the $\mathrm{RD}$, including the six patients assigned to level 3 in the phase I portion, the most frequent types of severe (grades 3 and 4) haematological toxicity were leucopenia (five cases, 20\%), neutropenia (five cases, 20\%), and thrombocytopenia (four cases, $16 \%)$, as shown in Table 4 . The most common types of nonhaematological toxicity were stomatitis (seven cases, $28 \%$ ), nausea (five cases, 20\%), and rash (five cases, 20\%). Among the 25 patients in the phase II portion, the dose of paclitaxel was reduced in three patients within one cycle because of neutropenia and thrombocytopenia. The incidence of the worst-grade toxicity in patients given the RD was none in seven patients $(28 \%)$, grade 1 in four $(16 \%)$, grade 2 in five $(20 \%)$, grade 3 in seven $(28 \%)$, and grade 4 in two $(8 \%)$. There was no treatment-related death or delayed severe toxicity.

\section{DISCUSSION}

This study was undertaken to determine the RD for phase II studies of paclitaxel combined with S-1 for advanced metastatic gastric cancer and to investigate the antitumour effect and feasibility of this combination. The RD was determined to be $60 \mathrm{mg} \mathrm{m}^{-2}$ of paclitaxel on days 1,8 , and 15 plus $80 \mathrm{mg} \mathrm{m}^{-2}$ day $^{-1}$ of S-1 on days $1-14$ of a 28-day cycle. The response rate at the RD was $54.1 \%$, with an MST of 15.5 months, and a TTP of 9.5 months. These are promising results in patients with advanced metastatic gastric cancer. Moreover, toxicity was not severe, and therapy could be administered on an outpatient basis.

Two late phase II trials of S-1 therapy in Japanese patients with advanced gastric cancer have reported a high overall response rate of $44-49 \%$ and an MST of 7-8 months (Sakata et al, 1998; Koizumi et al, 2000). These findings suggest that S-1 is one of the most effective currently available antitumour agents for gastric cancer. To further enhance efficacy and improve survival, several ongoing studies are assessing the response to $S-1$ combined with other anticancer agents with different mechanisms of action. Clinically, paclitaxel has been used in combination with 5fluorouracil (5-FU) and its derivatives for several reasons. First, paclitaxel is considered an effective drug for gastric cancer, with response rates ranging from 20 to $28 \%$ in single-agent phase II studies (Ajani et al, 1998; Ohtsu et al, 1998; Yamada et al, 2001; Yamaguchi et al, 2002). Furthermore, Ajani et al (2006a) reported that sequential treatment with paclitaxel and bryostatin-1 is effective, with a response rate of $29 \%$. Paclitaxel is a good candidate for combined treatment because of it lacks crossresistance to fluoropyrimidine derivatives. S-1 and paclitaxel have different mechanisms of action, and the principal toxicities of

Table 4 Adverse events observed in 25 patients

\begin{tabular}{lccc}
\hline & \multicolumn{3}{c}{ Number of patients (\%) } \\
\cline { 2 - 4 } Adverse events & Grade 3 & Grade 4 & Grade 3 or 4 \\
\hline Haematological & & & \\
$\quad$ Leucopenia & 5 & 0 & $5(20)$ \\
Neutropenia & 3 & 2 & $5(20)$ \\
Anaemia & 2 & 0 & $2(8)$ \\
Thrombocytopenia & 4 & 0 & $4(16)$ \\
Non-haematological & & & \\
Anorexia & 2 & 0 & $2(8)$ \\
Nausea & 4 & 1 & $5(20)$ \\
Diarrhoea & 1 & 0 & $1(4)$ \\
Fatigue & 2 & 0 & $2(8)$ \\
Stomatitis & 6 & 1 & $7(28)$ \\
Rash & 5 & 0 & $5(20)$ \\
\hline
\end{tabular}

National Cancer Institute common toxicity criteria (version 2). 
these drugs do not overlap (Fujitani et al, 2005). In recent years, weekly regimens of paclitaxel, based on its mechanism of action, have been widely studied. One study comparing a weekly infusion of paclitaxel with an infusion once every 3 weeks documented similar efficacy with decreased adverse reactions (in particular, myelosuppression and peripheral neuropathy) with the weekly regimen in women with ovarian cancer (Andersson et al, 2000). A combination of paclitaxel and 5-FU has been demonstrated to have additive cytotoxicity against tumour cell lines in vitro, especially strong with sequential exposure (Kano et al, 1996). Moreover, Kondo et al (2005) reported a MST of 335 days in a phase I study of weekly paclitaxel plus 5-FU in patients with advanced gastric cancer. The second reason for combining paclitaxel with 5-FU is that their principal toxicities differ considerably. Neuropathy and neutropenia are the principal toxicities of paclitaxel, whereas stomatitis and diarrhoea are the predominant toxicities of fluoropyrimidines in most commonly used regimens (Bokemeyer et al, 1997; Cascinu et al, 1998). We therefore combined paclitaxel with S-1.

As most toxic effects of S-1 occurred after 4 consecutive weeks of treatment in phase II studies, S- 1 was administered daily at a fixed dose of $80 \mathrm{mg} \mathrm{m}^{-2}$ for 2 consecutive weeks in combination with paclitaxel on days 1,8 , and 15 of a 28 -day cycle. This duration of treatment with S-1 was 2 weeks shorter than the time at which toxicity such as leucopenia generally appears. We studied this regimen in a phase I/II trial in patients with unresectable or recurrent advanced gastric cancer.

The main objective of our phase I study was to evaluate the safety and optimal dose of paclitaxel in combination with S-1. The incidences of grades 3 and 4 toxic effects in our study are consistent with those reported previously for the same S-1 combination regimen (Ajani et al, 2006b; Inokuchi et al, 2006). When paclitaxel was administered every 3 weeks with or without 5 -FU, non-haematological toxicity, apart from alopecia of grade 3 or higher, included neuropathy $(0-29 \%)$, myalgia $(0-27 \%)$, and nausea/vomiting (0-7\%) (Ohtsu et al, 1998; Yamada et al, 2001; Arai et al, 2003; Hokita et al, 2005; Kondo et al, 2005; Inokuchi et al, 2006). Although there are limitations in comparing the results of different studies because of differences in factors such as the dose and treatment schedule of paclitaxel therapy and the extent of prior treatment, neuromuscular toxicity, the most common adverse effect of paclitaxel, was very mild in our study. The good tolerability of our regimen is reflected in the fact that patients received a median of six treatment courses in the phase II portion.

An MST of at least 12 months and a TTP of at least 8 months would strongly suggest a significant advance in the treatment of advanced gastric cancer (Ajani et al, 2006b). In our phase I/II study, the response rate was $54.1 \%$ and the MST was 15.5 months.
The MST in our study was longer than that in previous phase II studies of S-1 as a single agent (207-250 days) (Sakata et al, 1998; Koizumi et al, 2000). Our response rate is equivalent to that reported for TS-1/cisplatin therapy (Koizumi et al, 2003). Moreover, the MST in our study was longer than the 383 days obtained in a previous study of S-1 combined with cisplatin (Koizumi et al, 2003). The incidences of grade 3 or 4 haematological and nonhaematological toxicity were similar to those with S-1 plus cisplatin (Koizumi et al, 2003; Ajani et al, 2006b). The high response rate and longer MST in our study may be related to the better performance status of our patients as compared with that in other studies. With cisplatin-based regimens, patients must receive intravenous infusions to ensure adequate hydration and prevent cisplatin-induced renal damage. S-1 combined with paclitaxel might therefore be better suited for treatment on an outpatient basis than cisplatin-based chemotherapy. A high response rate coupled with a better quality of life is considered an advantage of S-1 plus paclitaxel.

In 2005, Hokita et al (2005) reported the results of a phase I study of S-1 combined with paclitaxel in patients with advanced gastric cancer. The response rate was 53\%, and the MST was 428 days. Furthermore, Fujitani et al (2005) reported a preliminary response rate of $62.5 \%$ (five out of eight) in their phase I study of S-1 plus weekly paclitaxel in patients with advanced gastric cancer. These response rates and MST are comparable to those in our study. A variety of taxane-based combination chemotherapy regimens have been developed for advanced gastric cancer, steadily improving response rates. Ajani et al (2005) reported that a combination of docetaxel, cisplatin, and fluorouracil is highly active against advanced untreated gastric or gastroesophageal adenocarcinoma. Docetaxel has also been combined with TS-1, and available evidence indicates that this combination is effective and well tolerated in patients with advanced gastric cancer (Yamaguchi et al, 2006).

In conclusion, our phase I/II trial suggests that S-1 combined with paclitaxel is effective and well tolerated. Because this was a small, uncontrolled study, phase III trials of S-1 plus paclitaxel are needed to confirm benefits in terms of survival and quality of life in patients with advanced gastric cancer, thereby establishing the value of this new regimen. At present, a randomised study comparing TS-1 plus paclitaxel with TS-1 plus cisplatin is being carried out by the North Kanto Gastric Cancer Study Group.

\section{Conflict of interest statements}

E Mochiki, T Ohno, Y Kamiyama, R Aihara, N Haga, J Ojima, J Nakamura, H Ohsawa, T Nakabayashi, T Asao, and H Kuwano hereby declare not to be engaged in any financial or personal relationship with other people or organisations that could inappropriately influence their work.

\section{REFERENCES}

Ajani JA, Fairweather J, Dumas P, Patt YZ, Pazdur R, Mansfield PF (1998) Phase II study of Taxol in patients with advanced gastric carcinoma. Cancer J Sci Am 4: 269-274

Ajani JA, Fodor MB, Tjulandin SA, Moiseyenko VM, Chao Y, Filho SC Majlis A, Assadourian S, Van Cutsem E (2005) Phase II multiinstitutional randomized trial of docetaxel plus cisplatin with or without fluorouracil in patients with untreated, advanced gastric, or gastroesophageal adenocarcinoma. J Clin Oncol 23: 5660-5667

Ajani JA, Jiang Y, Faust J, Chan BB, Ho L, Yao JC, Rousey S, Dakhill S, Cherny RC, Craig C, Bleyer A (2006a) A multi-center phase II study of sequential paclitaxel and bryostatin-1 (NSC 339555) in patients with untreated, advanced gastric or gastroesophageal junction adenocarcinoma. Invest New Drugs 24: 353-357

Ajani JA, Lee FC, Singh DA, Haller DG, Lenz HJ, Benson III AB, Yanagihara R, Phan AT, Yao JC, Strumberg D (2006b) Multicenter phase II trial of S-1 plus cisplatin in patients with untreated advanced gastric or gastroesophageal junction adenocarcinoma. J Clin Oncol 24: $663-667$

Andersson H, Boman K, Ridderheim M, Rosenberg P, Sorbe B, Puistola U (2000) An updated analysis of a randomized study of single agent paclitaxel given weekly vs every 3 weeks to patients with ovarian cancer treated with prior platinum therapy. Proc Am Soc Clin Oncol 19: 380a

Arai T, Hamaguchi T, Shirao K, Shimada Y, Yamada Y, Muro K (2003) Weekly paclitaxel in patients with heavily treated advanced gastric cancer. Proc Am Soc Clin Oncol 22: 321

Bokemeyer C, Hartmann JT, Lampe CS, Clemens MR, Quietzsch D, Forkman L, Knaz L (1997) Paclitaxel and weekly 24-hour infusion of 5-fluorouracil/folinic acid in advanced gastric cancer. Semin Oncol 24: 96- 100

Cascinu S, Graziano F, Cardarelli N, Marcellini M, Giordani P, Menichetti ET, Catalano G (1998) Phase II study of paclitaxel in pretreated advanced gastric cancer. Anticancer Drugs 9: 307-310 
Chang AY, Kim K, Glick J, Anderson T, Karp D, Johnson D (1993) Phase II study of taxol, merbarone, and piroxantrone in stage IV non-small-cell lung cancer: The Eastern Cooperative Oncology Group Results. J Natl Cancer Inst 85: 388-394

Chollet P, Schoffski P, Weigang-Kohler K, Schellens JH, Cure H, Pavlidis N, Grunwald V, De Boer R, Wanders J, Fumoleau P, EORTC Early Clinical Studies Group (2003) Phase II trial with S-1 in chemotherapy-naive patients with gastric cancer. A trial performed by the EORTC Early Clinical Studies Group (ECSG). Eur J Cancer 39: 1264-1270

Einzig AI, Wiernik PH, Sasloff J, Runowicz CD, Goldberg GL (1992) Phase II study and long-term follow-up of patients treated with taxol for advanced ovarian adenocarcinoma. J Clin Oncol 10: 1748-1753

Fennelly D, Aghajanian C, Shapiro F, O'Flaherty C, McKenzie M, O’Connor C, Tong W, Norton L, Spriggs D (1997) Phase I and pharmacologic study of paclitaxel administered weekly in patients with relapsed ovarian cancer. J Clin Oncol 15: 187-192

Fujitani K, Narahara H, Takiuchi H, Tsujinaka T, Satomi E, Gotoh M, Hirao M, Furukawa H, Taguchi T (2005) Phase I and pharmacokinetic study of S-1 combined with weekly paclitaxel in patients with advanced gastric cancer. Oncology 69: 414-420

Hironaka S, Zenda S, Boku S, Fukutomi A, Yoshino T, Onozawa Y (2006) Weekly paclitaxel as second-line chemotherapy for advanced or recurrent gastric cancer. Gastric Cancer 9: 14-18

Hokita S, Aikou T, Miyazono F, Ishigami S, Aridome K, Maenohara S, Saihara T, Suenaga K, Nomura H, Maeda S, Takatori H, Arima H, Uchikado Y, Natsugoe S, Takano S (2005) A phase I combination chemotherapy study of biweekly paclitaxel and S-1 administration in patients with advanced gastric cancer. Cancer Chemother Pharmacol 57: $736-740$

Holmes FA, Walters RS, Theriault RL, Forman AD, Newton LK, Raber MN, Buzdar AU, Frye DK, Hortobagyi GN (1991) Phase II trial of taxol, an active drug in the treatment of metastatic breast cancer. $J$ Natl Cancer Inst 83: $1797-1805$

Horikoshi N, Mitachi Y, Sakata Y (1996) S-1, new oral fluoropyrimidine, is very active in patients with advanced gastric cancer (early phase II study). Proc Am Soc Clin Oncol 15: 466

Inokuchi $\mathrm{M}$, Yamashita $\mathrm{T}$, Yamada $\mathrm{H}$, Kojima $\mathrm{K}$, Ichikawa $\mathrm{W}$, Nihei Z, Kawano T, Sugihara K (2006) Phase I/II study of S-1 combined with irinotecan for metastatic advanced gastric cancer. Br J Cancer 94: $1130-1135$

Kano Y, Akutsu M, Tsunoda S, Matsui J, Suzuki K, Ikeda T, Inoue Y, Adachi K (1996) Schedule-dependent interaction between paclitaxel and 5-fluorouracil in human carcinoma cell lines in vitro. Br J Cancer 74: $704-710$

Kim NK, Park YS, Heo DS, Suh C, Kim SY, Park KC, Kang YK, Shin DB, Kim HT, Kim HJ (1993) A phase III randomized study of 5-fluorouracil and cisplatin versus 5 -fluorouracil, doxorubicin, and mitomycin $\mathrm{C}$ versus 5 -fluorouracil alone in the treatment of advanced gastric cancer. Cancer 71: $3813-3818$

Koizumi W, Kurihara M, Nakano S, Hasegawa K (2000) Phase II study of S-1, a novel oral derivative of 5-fluorouracil, in advanced gastric cancer. Oncology 58: $191-197$

Koizumi W, Tanabe S, Saigenji K, Ohtsu A, Boku N, Nagashima F, Shirao K, Matsumura Y, Gotoh M (2003) Phase I/II study of S-1 combined with cisplatin in patients with advanced gastric cancer. Br J Cancer 89: 2207-2212

Kondo K, Kobayashi M, Kojima H, Hirabayashi N, Kataoka M, Araki K, Matsui T, Takiyama W, Miyashita Y, Nakazato H, Nakao A, Sakamoto J (2005) Phase I evaluation of continuous 5-fluorouracil infusion followed by weekly paclitaxel in patients with advanced or recurrent gastric cancer. Jpn J Clin Oncol 35: 332-337

Ohtsu A, Boku N, Tamura F, Muro K, Shimada Y, Saigenji K, Akazawa S, Kitajima M, Kanamaru R, Taguchi T (1998) An early phase II study of a 3-h infusion of paclitaxel for advanced gastric cancer. Am J Clin Oncol 21: $416-419$

Ohtsu A, Shimada Y, Shirao K, Boku N, Hyodo I, Saito H, Yamamichi N, Miyata Y, Ikeda N, Yamamoto S, Fukuda H, Yoshida S (2003) Japan Clinical Oncology Group Study (JCOG9205). Randomized phase III trial of fluorouracil alone versus fluorouracil plus cisplatin versus uracil and tegafur plus mitomycin in patients with unresectable, advanced gastric cancer: The Japan Clinical Oncology Group Study (JCOG9205). J Clin Oncol 21: 54-59

Parker SL, Tong T, Bolden S, Wingo PA (1997) Cancer Statistics, 1997. CA Cancer J Clin 46: 5-27

Ross P, Nicolson M, Cunningham D, Valle J, Seymour M, Harper P, Price T, Anderson H, Iveson T, Hickish T, Lofts F, Norman A (2002) Prospective randomized trial comparing mitomycin, cisplatin, and protracted venous-infusion fluorouracil (PVI 5-FU) with epirubicin, cisplatin, and PVI 5-FU in advanced esophagogastric cancer. J Clin Oncol 20: $1996-2004$

Sakata Y, Ohtsu A, Horikoshi N, Sugimachi K, Mitachi Y, Taguchi T (1998) Late phase II study of novel oral fluoropyrimidine anticancer drug S-1 (1M Tegafur-0.4M Gimestat-1M otastatpotassium) in advanced gastric cancer patients. Eur J Cancer 34: 1715-1720

Sugimachi K, Maehara Y, Horikoshi N, Shimada Y, Sakata Y, Mitachi Y, Taguchi T (1999) An early phase II study of oral S-1, a newly developed 5 -fluorouracil derivative for advanced and recurrent gastrointestinal cancers. The S-1 Gastrointestinal Cancer Study Group. Oncology 57: $202-210$

Takechi T, Nakano K, Uchida J, Mita A, Toko K, Takeda S, Unemi N, Shirasaka T (1997) Antitumor activity and low intestinal toxicity of S-1, a new formulation of oral tegafur, in experimental tumor models in rats. Cancer Chemother Pharmacol 39: 205-211

Therasse P, Arbuck SG, Eisenhauer EA, Wanders J, Kaplan RS, Rubinstein L, Verweij J, Van Glabbeke M, van Oosterom AT, Christian MC, Gwyther SG (2000) New guidelines to evaluate the response to treatment in solid tumors. European Organization for Research and Treatment of Cancer, National Cancer Institute of the United States, National Cancer Institute of Canada. J Natl Cancer Inst 92: 205-216

Vanhoefer U, Rougier P, Wilke H, Ducreux MP, Lacave AJ, Van Cutsem E, Planker M, Santos JG, Piedbois P, Paillot B, Bodenstein H, Schmoll HJ, Bleiberg H, Nordlinger B, Couvereur ML, Baron B, Wilis JA (2000) Final results of a randomized phase III trial of sequential high-dose methotrexate, fluorouracil, and doxorubicin versus etoposide, leucovorin, and fluorouracil versus infusional fluorouracil and cisplatin in advanced gastric cancer: a trial of the European Organization for Research and Treatment of Cancer Gastrointestinal Tract Group. J Clin Oncol 18: $2648-2657$

Wani MC, Taylor HL, Wall ME, Coggon P, McPhail AT (1971) Plant antitumor agents. VI. The isolation and structure of taxol, a novel antileukemic and antitumor agent from Taxus brevifolia. J Am Chem Soc 93: $2325-2327$

Webb A, Cunningham D, Scarffe JH, Harper P, Norman A, Joffe JK, Hughes M, Mansi J, Findley M, Hill A, Oates J, Nicolson M, Hickish T, O'Brien M, Iveson T, Watson M, Underhill C, Wardley A, Meehan M (1997) Randomized trial comparing epirubicin, cisplatin, and fluorouracil vs fluorouracil, doxorubicin, and methotrexate in advanced esophagogastric cancer. J Clin Oncol 15: 261-267

Wils JA, Klein HO, Wagener DJ, Bleiberg H, Reis H, Korsten F, Conroy T, Fickers M, Leyvraz S, Buyse M (1991) Sequential high-dose methotrexate and fluorouracil combined with doxorubicin - a step ahead in the treatment of advanced gastric cancer: a trial of the European Organization for Research and Treatment of Cancer Gastrointestinal Tract Cooperative Group. J Clin Oncol 9: 827-831

Yamada Y, Shirao K, Ohtsu A, Boku N, Hyodo I, Saitoh H, Miyata Y, Taguchi T (2001) Phase II trial of paclitaxel by 3-h infusion for advanced gastric cancer with short premedication for prophylaxis against paclitaxel-associated hypersensitivity reactions. Ann Oncol 12: $1133-1137$

Yamaguchi K, Shimamura T, Hyodo I, Koizumi W, Doi T, Narahara H, Komatsu Y, Kato T, Saitoh S, Akiya T, Munakata M, Miyata Y, Maeda Y, Takiuchi H, Nakano S, Esaki T, Kinjo F, Sakata Y (2006) Phase I/II study of docetaxel and S-1 in patients with advanced gastric cancer. Br J Cancer 94: $1803-1808$

Yamaguchi K, Tada M, Horikoshi N, Otani T, Takiuchi H, Saitoh S, Kanamaru R, Kasai Y, Koizumi W, Sakata Y, Taguchi T, Paclitaxel Gastric Cancer Study Group in Japan (2002) Phase II study of paclitaxel with 3-h infusion in patients with advanced gastric cancer. Gastric Cancer 5: 90-95 